\title{
UNA NOVELA CORTA SOBRE LA DICTADURA CHILENA: SANTIAGO CERO DE CARLOS FRANZ
}

\section{Carmen de Mora}

Universidad de Sevilla

demora@us.es

Resumen: Mediante el análisis de Santiago Cero de Carlos Franz, me propongo en este trabajo examinar los rasgos que presenta la novela corta chilena escrita hacia fines del siglo $\mathrm{XX}$, tras el quiebre social producido durante la Dictadura. Una narrativa cuyo objetivo es representar el "apagón cultural" y la atmósfera opresiva vivida por la sociedad chilena bajo el régimen militar. La novela fue publicada dos años más tarde del famoso plebiscito de 1988 que puso fin a la dictadura militar y dio paso a la transición democrática con el gobierno de Patricio Aylwin. Sin embargo, los hechos se sitúan hacia fines de los setenta, durante el gobierno militar. A través de las vidas desesperanzadas de un grupo de jóvenes estudiantes, el autor recrea en esta obra la mediocridad, el aislamiento y la falta de horizonte en que discurría la vida universitaria, sometida a un firme control por parte de las autoridades académicas.

Palabras clave: nueva narrativa chilena, novela corta, memoria, punto de vista, tiempo y narración, espacio simbólico

\section{A SHORT NOVEL ABOUT THE CHILEAN DICTATORSHIP: SANTIAGO CERO BY CARLOS FRANZ}

\begin{abstract}
Through the analysis of Santiago Cero by Carlos Franz, I intend in this work to examine the traits presented by the Chilean short novel written towards the end of the twentieth century, after the social break produced during the Dictatorship. A narrative that aims to represent the "cultural blackout" and the oppressive atmosphere experienced by the Chilean society under military regime. The novel was published two years after the famous plebiscite of 1988 that ended the military dictatorship and gave way to the democratic transition with the government of Patricio Aylwin. However, the plot is set towards the late 1970s, during the military rule. Through the hopeless lives of a group of young students, the author recreates in this work the mediocrity, isolation and lack of horizon in which university life ran, subject to strong control by the academic authorities.
\end{abstract}

Keywords: new Chilean narrative, short novel, memory, time and storytelling, point of view, symbolic space 
DOI: https://doi.org/10.24029/lejana.2020.13.440

Recibido: el 2 de noviembre de 2018

Aceptado: el 1 de marzo de 2019

Publicado: el 19 de febrero de 2020 


\section{Introducción}

Santiago Cero fue publicada por primera vez en 1990 (Santiago, Publicaciones Nuevo Extremo), tras haber obtenido en Lima, en 1988, el Premio CICLA, otorgado por el Consejo de Investigación Cultural Latinoamericana. Su acogida por parte de la crítica chilena fue muy exitosa y ha llegado a considerarse un testimonio generacional. ${ }^{1}$ Hubo una primera versión que no satisfacía al autor, y en 1987 retomó el manuscrito para transformarlo en la novela corta actual. ${ }^{2}$ Su obra se inscribe en la denominada nueva narrativa chilena, ${ }^{3}$ celebrada con la euforia propia de un manifiesto vanguardista por el escritor chileno Jaime Collyer en "Casus belli: todo el poder para nosotros", donde destaca el carácter cosmopolita, universalizante e internacionalista de la nueva generación.

Franz pertenece a la generación de 1987 o de la orfandad (los nacidos entre 1950 y 1964) (Cánovas, 1997), marcada por el golpe militar de 1973 en Chile y las consecuencias derivadas de la implantación del régimen dictatorial. Mario Osses, en "Nosotros, los finiseculares", estableció las coordenadas de estos escritores:

Los narradores de la generación de 1987 somos una promoción que nació y se formó en la encrucijada de dos épocas distintas, contrapuestas entre sí. De una parte, somos la espuma que dejó la efervescencia de las mareas de los años 60 sobre la playa de la utopía; y de otra, la resaca profunda de lo que sobrevino en 1973, dentro de nuestras fronteras; y más allá de ellas la sensación generalizada de inestabilidad, que, como producto residual del orden disuasorio de Occidente, ha experimentado el hombre moderno. (1990: 140)

Carlos Franz se formó como escritor bajo el denominado "apagón cultural" que se produjo durante los años de la dictadura, Jaime Collyer reduce a unos cuantos rasgos el común denominador de su generación, que es la de Franz: el escepticismo, el sentimiento de orfandad y las controversias intrageneracionales, provocadas estas por la división entre los escritores que permanecieron en Chile y los que emigraron al exterior (1990: 123-135).

En Santiago Cero el contexto del régimen militar queda más bien implícito, aunque desde luego impregna la atmósfera de la novela y se trasluce en la actitud de los personajes. ${ }^{4}$ Tratándose de una novela escrita hacia el final de la dictadura, que tiene que ver con la memoria de la historia reciente del país, no es, sin embargo, testimonial en sus planteamientos. Lo que no impide que ayude a reconstruir distintos aspectos de aquella realidad traumática en los años setenta practicando un tipo de "memoria activa", en términos de Nelly Richard. Aquella que no se limita a ser el mero depósito acumulativo de hechos sucedidos, sino que busca ser ella misma intervención, suceso y actualidad: "El recuerdo necesita construir vínculos de sentido que reinserten el fragmento del pasado en nuevas tramas interpretativas haciéndole decir lo que antes ignoraba o callaba, auxiliándolo con

\footnotetext{
${ }^{1}$ Léase al respecto el "Posfacio" de Alfredo Jocelyn-Holt Letelier, firmado en septiembre de 1997, que se añadió en la edición publicada en la Editorial Seix Barral.

${ }^{2}$ Franz escribió esa primera versión ocho o nueve años antes de que le concedieran el premio, cuando asistía al taller que impartía José Donoso. Estaba escrito como un cuento largo: "lo realicé como un ajuste de cuentas por la gran frustración que fue la universidad para mí y los jóvenes de mi generación" (Gambetti, 1989: 36).

${ }^{3}$ El propio autor así lo reconoce en su artículo "Novelas del fín del mundo" (véase en la bibliografía).

${ }^{4}$ Es así al menos hasta el capítulo sexto, en que Sebastián prepara el atentado contra la Escuela, y sobre todo en el capítulo octavo, donde se sitúa el verdadero clímax de la novela, en la catarata de mierda cayendo desde lo alto de la torre de la Escuela.
} 
reconceptualizaciones inéditas de lo transcurrido, llevándolo a argumentar rescates y omisiones" (Richard, 1995: 33).

\section{El punto de vista y la función del pronombre personal en Santiago Cero}

La novela fue publicada dos años más tarde del famoso plebiscito de 1988 que puso fin a la dictadura militar y dio paso a la transición democrática con el gobierno de Patricio Aylwin. Sin embargo, los hechos se sitúan hacia fines de los setenta, durante el gobierno militar. El autor recrea en esta obra la mediocridad, el aislamiento y la falta de horizonte en que discurría la vida universitaria, sometida a un firme control por parte de las autoridades académicas. Nelly Richard se ha referido a ello en La insubordinación de los signos:

La Universidad intervenida por la toma de poder militar perdió su rol de conducción nacional en el movimiento de las ideas mientras tenía lugar, en sus extramuros, el explosivo surgimiento de lo que Rodrigo Cánovas llamó un "discurso de la crisis" [...] un discurso que se confrontó a la exterioridad viva — desamurallada — de los procesos y sucesos negados por la clausura universitaria [...]. (1994: 70)

Franz se centra principalmente en lo que sucede dentro del recinto universitario, aunque no faltan referencias a la realidad exterior, de forma que aquel se puede considerar un microcosmos de la atmósfera opresiva que afectaba al país en su conjunto bajo la dictadura. Estructurada en tres partes, constituidas por breves capítulos, la obra consta, además, de un prefacio y un epílogo. Tanto el primero como el cierre del epílogo — de tan solo cinco líneas - van en cursiva y corresponden al presente del narrador, quien, transcurridos siete años desde que finalizó los estudios, se encuentra confinado en una isla cumpliendo condena. Ambos elementos le confieren al texto una estructura circular, reforzada en el prefacio por la utilización del mito de Sísifo, que abre la novela. ${ }^{6}$ El resto de la narración se centra en los recuerdos del pasado trasladados a las cartas que se escribe a sí mismo y que permiten comprender su situación actual. La narración discurre, por tanto, en dos modalidades temporales, el presente de la isla y el pasado evocado, desde ese mismo espacio, sobre hechos que tienen lugar en la cafetería de la Escuela de Derecho, principalmente, y en la ciudad de Santiago. El sujeto de la enunciación es un narrador innominado - a quien sus amigos llaman "el artista" por su afición a la poesía — que cumple condena a trabajos forzados en una isla antes aludí a ello- por haber colaborado estrechamente con el gobierno de la dictadura chilena realizando, entre otras tareas, la de soplón. Desde allí, a través de las cartas, recrea su “educación sentimental”, que transcurre a finales de los setenta, durante los años estudiantiles en la Escuela de Derecho de la Universidad de Santiago —donde también estudió Carlos Franz-, y que, según él, constituye el origen de su situación en el presente. En el prefacio, por tanto, se anticipan los dos ejes que vertebran la novela: la historia de amor y el trasfondo político en que el narrador se transforma en un alto funcionario al servicio del dictador. Es

\footnotetext{
${ }^{5}$ Sobre la situación de la Universidad chilena en los años setenta escribe Rodrigo Cánovas: "En septiembre de 1973, las universidades fueron ocupadas militarmente. Los profesores de izquierda fueron detenidos, expulsados o acosados. Salvo excepción, todos los comunistas fueron expulsados; hubo también mucha gente joven que perdió sus cargos" (1990: 163).

6 Entre los alicientes de la novela corta se encuentra la adopción de esquemas como la oposición, el entrecruzamiento, el paralelismo, la gradación o el círculo, dispositivos que refuerzan la semiosis narrativa y favorecen la inteligibilidad del relato (Grojnowski, 2000: 38).
} 
preciso señalar que la narración tan solo adopta una forma epistolar en el prefacio y en el segmento final de la novela.

"Santiago-O" es en la novela el nombre de la prefectura especial en la que trabajaba el siniestro personaje Blanco y a la vez la clave que utilizaba para comunicarse con el narrador. Más tarde será este quien trabajará en la misma prefectura y terminará desplazando a Blanco. Sin embargo, el hecho de que en el título de la novela no se utilice la cifra, sino las letras (cero), le da un alcance simbólico alusivo a la situación de parálisis y de falta de expectativas por la que atravesaba la capital chilena (y con ella el país) bajo la dictadura. En más de una ocasión se alude a la ausencia de ilusiones de los jóvenes en ese momento y, por extensión, de la sociedad en su conjunto.

En Santiago Cero, por tanto, la enunciación se encuentra a cargo de un personaje que, careciendo de cualidades destacables, se sitúa, sin embargo, en el centro del mundo descrito, y desde su punto de vista vamos conociendo las vidas de un grupo de jóvenes universitarios durante los años setenta en Chile, es decir, pertenecientes a la misma generación que el autor de la obra. ${ }^{7}$ Por ser poco frecuente, la utilización de la segunda persona constituye uno de los rasgos más peculiares que presenta este texto. Es posible que Franz se inspirara en $L a$ modification (1957) de Michel Butor, pues, aunque son muy distintas, además de la narración en segunda persona, comparten la existencia de un triángulo amoroso en la trama y la transformación del protagonista a medida que avanza la novela. Otro texto paradigmático en la utilización de la segunda persona narrativa es Aura (1962), la famosa novela corta de Carlos Fuentes. El personaje femenino que inspira el título también sufre una transformación escalofriante en los brazos del narrador, aunque de carácter físico, mientras que en Butor y en Franz resulta más bien de índole espiritual y moral.

El plano de la enunciación en Santiago Cero es complejo, corresponde a un yo que se dirige a un tú que no es el lector, como cabría pensar en un principio, sino él mismo, ya que en la isla pasa parte de su tiempo escribiéndose cartas sobre ciertos episodios de su pasado que lo han marcado y que constituyen el enunciado. De ese modo, las informaciones que puede obtener el lector le llegan exclusivamente a través de la perspectiva del narradorprotagonista. Tan solo en el prefacio y al final del epílogo, es decir, los dos momentos de la novela que adoptan la forma epistolar — marcada con letra cursiva - y que corresponden al presente y no al pasado, habla en primera persona.

De la misma forma que el protagonista de La modification está encerrado en un vagón de tren, que, simbólicamente, representa la idea de estar encerrado en su propia conciencia, el de la novela chilena lo está en una barraca, además del aislamiento que de por sí representa la isla. Por otra parte, según he comentado supra, la narración discurre en dos planos temporales y en dos espacios diversos, por consiguiente, se trata de dos niveles de realidad distintos y alejados. De ese modo, el narrador que cuenta la historia desde el presente y el personaje que

\footnotetext{
${ }^{7}$ Inicialmente forman el grupo Raquel, Rubén, Wilson, América y el narrador (conocido por "el artista" porque escribía poemas), al que más tarde se une Sebastián, quienes solían reunirse en la cafetería de la Escuela sentados en una mesa situada al fondo presidida por un afiche de Lufthansa del castillo Neuschwanstein mandado construir por Luis II de Baviera. El Neuschwanstein se convierte en un leitmotiv que representa a una Europa idealizada, el lugar de la cultura, de los sueños y la esperanza al que todos querrían marcharse para huir de Chile. Por otra parte, la cafetería — con otros espacios públicos - es uno de los lugares recurrentes de la novela corta (Tibi, 1995: 51-53).
} 
la vivió en el pasado no son los mismos, ni tampoco su situación afectiva. ${ }^{8}$ Sin embargo, no son independientes uno de otro, sino que están íntimamente imbricados, siendo en buena medida el presente una consecuencia del pasado. En ese sentido, el narrador no solo evoca los recuerdos y cuenta su historia, sino que, al mismo tiempo, se autoanaliza: "Tú andabas buscando todavía a la mujer ideal, en esos tiempos" (1997: 22), "Y ahora descubres que aquella pregunta ya envolvía el vicio secreto de tu generación. Aquel que llegaría a convertirse más tarde en la mejor herramienta de tu oficio: el deseo inconfesable de que la autoridad les cayera encima a todos, por parejo" (26-27). Es decir, se produce una dramatización del narrador, una intromisión del presente en el pasado.

Al lector de esta historia le pueden surgir varias preguntas que no están del todo resueltas en ella: ¿por qué el narrador escribe cartas que no enviará y por qué las escribe solo para sí mismo? ${ }^{10}$ Puesto que a través de ellas se enfrenta con su propio pasado, ¿se da en él alguna forma de arrepentimiento por haber colaborado con el dictador o volvería a actuar como lo hizo si fuera necesario?, ¿qué opinión le merece su conducta? En el prefacio nos ofrece algunas pistas sobre la primera pregunta:

Todo el que haya tenido que llevar durante años una doble vida me comprenderá. Sabrá que es irremediable aficionarse a hablar solo, dirigirse a uno mismo como si todo el tiempo lo hiciéramos a un cómplice con el que vamos esposados.

También es una medida de seguridad. Sé que revisan nuestras cosas durante los turnos. Por si inadvertidamente hiciera recuerdos comprometedores, prefiero tomar la vieja precaución de imputárselos a otro... (12)

Sin embargo, estas justificaciones no satisfacen las restantes preguntas. Sí habla del asunto cuando se refiere a sus compañeros de prisión: “Unos caen en los arrepentimientos más extemporáneos; otros se jactan de sus antiguas hazañas" (11). ¿Y él, se arrepiente de algo?

En el epílogo de la novela, ante la reacción de Raquel, al enterarse de que él llevaba una doble vida, la principal coartada para justificar su actuación, que había sido luchar por el amor de ella alejando a su rival, Sebastián, se desmorona: "Tendrías que admitir que no fue solamente para obtener su amor, que no fue nada más para asegurarlo y conservarlo que hiciste lo que hiciste durante todos esos años. Quedarías obligado a confesarte que tus verdaderos motivos fueron los otros, los vulgares, los mismos de tus subalternos" (154-155). En efecto, cuando Raquel descubre que él le había estado ocultando las cartas de Sebastián, le asegura que nunca lo habría dejado por esas cartas, que hacía mucho que no pensaba en Sebastián. Así, de repente, el narrador supo que su vida había sido un fracaso y que la coartada de los celos ya no le servía para justificarse. El último párrafo de la novela, un tanto enigmático, vuelve al presente: "hoy me llegó después de tantos años una carta tuya. El hielo hará imposible que salgamos al trabajo. Podré aprovechar las cortas horas de esta luz gris, contestándote" (157). No sabemos si la carta mencionada es real o imaginaria; en caso de ser

\footnotetext{
${ }^{8}$ Véanse al respecto los comentarios de Françoise Van Rossum-Guyon a La modification (1970: 134).

${ }^{9}$ En lo sucesivo, en las citas donde únicamente aparece el número de página, se hará referencia a la edición de 1997 de Santiago Cero de Carlos Franz, véase en la bibliografía.

${ }^{10}$ En una clara anticipación de su vida posterior en el penal, cuando era estudiante de derecho el narrador vivía en un desván que daba a la azotea, y allí escribía poemas y diarios dirigidos a un yo futuro (83). La paradoja es que el hecho posterior -la reclusión- aparece ya en el prefacio de la obra, por lo que la anticipación pierde su efecto y queda neutralizada.
} 
real podría pertenecer a Raquel, lo que introduciría un atisbo de esperanza sobre la posible redención del personaje, según ha reconocido el propio autor (Gambetti, 1989: 36).

Sin embargo, las formas verbales condicionales dejan al descubierto su falta de valor e incapacidad para enfrentarse a la verdad. Además, sus palabras y opiniones no son del todo fiables, porque, en consonancia con su afición a la literatura - como le ocurría a Roberto Michel, protagonista de "Las babas del diablo" de Julio Cortázar-, a lo largo de la narración da muestras de su facilidad para cambiar la versión de los hechos cuando viene al caso o cuando le conviene. Teniendo en cuenta estos precedentes, el desdoblamiento del yo en una segunda persona se explicaría por la incapacidad del personaje para autoconocerse y asumir su verdadera condición. Afirma Piglia que "el criminal siempre cuenta su historia como si fuera la de otro. Puede matar, pero no puede decir "he matado" (2016: 360). El narrador se ha quedado encerrado en el círculo vicioso de una conciencia que lo transporta una y otra vez a su época de estudiante, al día en que se malogró su destino y a todo lo que sucedió después: "Tú no siempre fuiste tú. Tú no siempre habitaste una isla. Tú fuiste una vez inocente. Lo eras antes de que llegara esa primera carta" (15). ${ }^{11}$ Así empieza el primer capítulo de la novela. La carta a la que se refiere es la primera de una serie que supuestamente escribía un amigo de Sebastián que se encontraba en Europa, aunque en realidad las redactaba el propio Sebastián para seducir a Raquel, quien — como todos los estudiantes del grupo — soñaba con marcharse de Chile y vivir en Europa. La rivalidad con Sebastián por conquistar a Raquel le hizo perder la inocencia y lo llevó a tratar por todos los medios de perjudicar al joven activista. Ese propósito finalmente lo condujo hasta Blanco, sobre el que corrían varios rumores. Uno de ellos era que a raíz del golpe se había convertido en delator de sus amigos, enviándolos a la tortura. Con este controvertido sujeto empezó a colaborar para el régimen y a llevar una doble vida. Sin embargo, no se aclara hasta dónde fue capaz de llegar, ya que, preso de una cobardía insuperable, parece haber querido borrar de su conciencia todo lo sucedido después de acabados los estudios en la Escuela de Derecho. ${ }^{12}$ ¿Pretende justificarse a sí mismo, olvidando ex profeso esas fechorías que a los ojos de Raquel y de otras muchas personas lo convirtieron en un ser despreciable? Así parece. Él mismo reconoce que su memoria se había detenido en los años de estudiante, como si, a fuerza de recordar, fuera posible cambiar la cadena de hechos que lo fueron arrastrando hasta la situación actual: "Mi memoria se detuvo años antes, en lo que podría llamar mi educación sentimental; pero esta no interesa en absoluto a los fiscales. Sin embargo, si existiera un juez que se ocupara de esos primeros móviles, de los pecados originales, de las causas remotas, en lugar de sus tardíos efectos, ante él me gustaría testimoniar" (11).

El problema que presenta esta justificación romántica y sentimental que el personaje se da a sí mismo es que, antes de que apareciera Sebastián en sus vidas, a pesar de su deseo, no había sido capaz de avanzar en la relación con Raquel más allá de la simple amistad, comportándose con una cobardía paralizante. En cierta ocasión, después de haber estado en el cine con ella sin haberse atrevido a declararle sus sentimientos, a pesar de que llevaba esa

\footnotetext{
${ }^{11}$ Las cartas cumplen una función distinta en la novela según los personajes que las escriben: las del narrador son una proyección de su conciencia, de los recuerdos que le obsesionan y, por tanto, de su identidad dividida. Las que escribe Sebastián, el activista político, tienen como objetivo ayudar a soñar, ofrecerles a sus amigos, y sobre todo a Raquel, la posibilidad de vivir en Europa una vida que realmente mereciera la pena.

${ }^{12}$ Sobre esta cuestión volveré más adelante, en el apartado "Tiempo y narración".
} 
intención, reconoció que su deseo profundo habría sido vivir para siempre en ese territorio ambiguo: "De hecho, jamás crecer, jamás abandonarlo" (43). Tal actitud — propia de quien padece el síndrome de Peter Pan - resulta contradictoria con el trabajo perverso y comprometido que realizó para el régimen. Asimismo, la resistencia a enfrentarse a la realidad atroz de su pasado más reciente, mientras cumplía castigo en la isla, delata su falta de entereza e inmadurez. No obstante, podría argumentarse que de alguna manera acepta su culpa, pues cuando en el último capítulo, en medio de la revuelta estudiantil, una alumna lo reconoce, él no se defiende: "«icuidado con ése, es un espía, un sapo!», advirtiendo a otro de sus compañeros que levantó en contra tuyo el asta de una bandera... No te defendiste" (156). ¿Fue por miedo o por consciencia del daño que había hecho? En todo caso, ese reconocimiento parece deberse más a un impulso inconsciente, puesto que no persiste a lo largo de la narración.

La utilización de la segunda persona narrativa, la fijación del punto de vista en una conciencia central — como en este caso-, si bien parece dirigirse al lector motivándolo a implicarse más en la historia, plantea el problema de que este se ve sometido a las limitaciones de la conciencia del personaje, de ahí que no dispongamos de las informaciones necesarias para juzgarlo con objetividad. ${ }^{13}$ Por otra parte, esta falta de desarrollo de los diversos aspectos de un tema no deja de ser un rasgo característico de la novela corta. En referencia a ello escribe Judith Leibowitz: "Whereas the novel explicitly discusses various aspects of experience until the reader is involved in the fictional reality, the novella involves the reader in a large area of experience without explicitly developing its facets" (1974: 52).

\section{Tiempo y narración}

El desarrollo temporal de Santiago Cero es solo parcialmente lineal, ya que el hilo de la narración se ve sometido a algunos saltos temporales. Carlos Franz ha reconocido la influencia de los escritores del Boom en su formación, ${ }^{14}$ sobre todo en los comienzos, y en ese sentido, la fórmula inicial de Cien años de soledad, "Muchos años después", y las alteraciones temporales que se derivan de ella alguna repercusión tienen en esta novela. El primer capítulo se sitúa en el último curso de la carrera, en el mes de mayo, el día en que el narrador descubre que Raquel y Sebastián estaban enamorados, y toma la decisión de recuperarla. Sin embargo, en el capítulo siguiente se produce una analepsis que nos traslada a los primeros recuerdos que tenía de Raquel con 17 años, cuando llegó a la Escuela. Como sucedía en Cien años de

\footnotetext{
${ }^{13}$ Van Rossum-Guyon (1970: 139): "Puisque toutes les informations sont relatives au personnage, puisqu'il est impossible de s'en remettre à un narrateur qui en sait plus long et nous fait voir «les deux côtés de l'étoffe», les qualités humaines et spirituelles du personnage médiateur sont dans ce cas déterminantes. [Puesto que todas las informaciones pertenecen al personaje, puesto que es imposible fiarse de un narrador". que sepa más y nos haga ver "les deux côtés de l'étoffe" (la traducción literal sería "los dos lados de la tela", sintagma equivalente a "las dos caras de la moneda", en castellano), las cualidades humanas y espirituales del personaje mediador son en este caso determinantes; traducción mía]. Véase también el apartado completo: 135-140.

${ }^{14}$ Antonio Avaria considera que se trata de una novela de formación, un Bildungsroman, y acertadamente compara al personaje de Sebastián con el de Jaguar de La ciudad y los perros, ya que aquel tampoco se deja bautizar al ingresar en la Escuela: "Hay una sutil afinidad argumental: un grupo de adolescentes en una Escuela y la ciudad, la iniciación a la vida en la hipocresía y la sofocación de todo sueño, la educación autoritaria, el tutelaje militar, el narrador poeta que transige con la inmoralidad" (1990: 151). El narrador de Santiago Cero coincide con Alberto, el protagonista de La ciudad y los perros, en que es poeta, pero también presenta rasgos que recuerdan a Roberto Michel de "Las babas del diablo" de Cortázar, como se verá más adelante.
} 
soledad, esa analepsis se produce dentro de una prolepsis o anticipación: "Años — siglosdespués, al comienzo de tu servicio, matabas el tedio de las eternas rondas nocturnas por la ciudad, reconstruyendo rasgo a rasgo la primera imagen que tuviste de Raquel. La que tenía cuando llegó a la Escuela, al primer curso" (19). En el capítulo tercero, evoca la llegada de Sebastián al centro, cuando ellos pasaban a tercero, y así continúa avanzando la historia hasta llegar al undécimo capítulo y alcanzar el punto en el que había comenzado la novela (capítulo primero). En los capítulos cuarto y quinto de la Segunda parte, los recuerdos del narrador se centran en los que le había comentado Sebastián sobre su familia y sobre la primera vez que vio a Raquel. Entre el último capítulo y el epílogo se produce una elipsis temporal de siete años que precede al desenlace en el que Raquel, a través de la Yolita, descubre la verdad y lo abandona. El siguiente salto temporal corresponde ya al presente del narrador cumpliendo su condena.

Las alteraciones temporales se relacionan con la importancia de los recuerdos durante la vida penitenciaria del protagonista-narrador, por ello sorprende la falta de información sobre los últimos siete años de su vida transcurridos desde que dejó la Universidad, precisamente los años de colaboración más intensa con el gobierno dictatorial. Probablemente, esa incapacidad para enfrentarse a su actuación en el pasado reciente resulte una representación simbólica de lo "no-dicho", del silencio y de lo reprimido acerca de los crímenes y la violación de los derechos humanos ocurridos en Chile bajo la dictadura. Incluso más tarde, durante algunos años, el consenso político de la Transición favoreció la impunidad de los culpables.

\section{El espacio simbólico}

Las referencias y descripciones espaciales en Santiago Cero permiten profundizar en la psicología y estado de ánimo de los personajes al tiempo que refuerzan la semiosis general de la novela. De entrada, encontramos dos espacios aparentemente contrapuestos que tienen su correlación en las dos modalidades temporales que confluyen en la obra: presente y pasado. El aquí y ahora del narrador se sitúa en la isla en la que está condenado a trabajos forzados. Un lugar con poca luz, donde los días son cortos, a veces el viento destruye durante la noche lo que los presos han levantado durante el día, y en el que nieva cuando llega el invierno; un lugar tan duro y tedioso como la vida de los presos que lo habitan. El otro espacio corresponde a la ciudad de Santiago. De ella se ofrecen tanto visiones generales, panorámicas o de sus calles, como de lugares concretos. Sin duda el más emblemático es la Escuela de Derecho, que a su vez se subdivide en tres espacios: primero, la zona central, vinculada metonímicamente a los personajes, es la cafetería, donde el grupo de amigos — entre ellos, el narrador - pasan la mayor parte del tiempo sentados en una mesa situada al fondo debajo de un afiche turístico de Lufthansa con una imagen del castillo de Neuschwanstein; segundo, el patio que queda fuera del edificio, donde se encuentra la fuente de la Dama Verde y que puede verse desde la cristalera de la cafetería; tercero, los entretechos, el lugar más misterioso del edificio, situado más arriba de la quinta planta, donde se encontraba la Sala de Profesores. Allí había instalado Sebastián su refugio, en lo alto de la torre del reloj, donde se albergaba el Fondo de Memorias de los Alumnos, cuyo laberinto de anaqueles con miles de legajos polvorientos recuerda la Biblioteca de Babel. Aún cabe añadir la Sala de Profesores en el 
último piso, desde cuyos ventanales las autoridades de la Escuela vigilaban el ritual de las novatadas de los estudiantes. Otros espacios menos significativos, aunque complementarios de los anteriores, son el pensionado universitario de la astróloga Yolita Manzur, donde se hospedaban el narrador y Rubén, y adonde después se iría también Sebastián. En el edificio, los dos primeros pisos de la vivienda y la mitad del tercero correspondían a la Casa de Reposo de la Doctora Sonia. La otra mitad del tercero, el cuarto y el quinto, al pensionado universitario de Yolita Manzur. El narrador ocupaba una habitación que daba a la azotea, y desde allí podía espiar toda la vida del caserón, así como las salidas y entradas de Raquel y Sebastián. Por último, el Travelers's Night Club, adonde el narrador es conducido por Blanco con la idea de asociarse con él e involucrarlo en sus actividades.

\section{La ciudad de Santiago}

La clave de la imagen que proyecta la novela de la ciudad de Santiago es la de la vigilancia, como corresponde a un régimen político amparado en el miedo y la delación: "era imposible en esos años seguir a alguien por Santiago, con los motivos que fuera, sin entrar inadvertidamente en una red. En un sistema de seguimientos y vigilancias en el que tú mismo terminarías acechado por otro y este por uno más, hasta llegar a quien sabe qué vigilante central que los seguía a todos" (76). De ahí que Rodrigo Cánovas, en un esclarecedor artículo sobre la novela, sostenga la hipótesis de que la Escuela de Leyes, tal como está representada, "realiza espacialmente el principio de sociedad vigilada" y se puede relacionar con el modelo del Panopticón, desarrollado por Foucault en Vigilar y castigar. Nacimiento de la prisión (1975) en cuanto técnica de control y de vigilancia en una sociedad (2000: 64). Una lectura muy convincente, teniendo en cuenta que las acciones relacionadas con la vigilancia son recurrentes por parte de las autoridades del centro y de los personajes de Blanco y el anónimo narrador, y generan la atmósfera asfixiante de la novela. Estos últimos vigilan también por las calles de Santiago, de forma que la Escuela se puede considerar un microcosmos que simboliza lo que sucedía a gran escala en el resto del país.

Todos los personajes ofrecen una visión negativa de la ciudad, siempre con el valle tapado por una nube de humo. Raquel la define como un pozo: "Un agujero perdido en las cordilleras, tajeado por una acequia” (88). Otras visiones están a cargo de Sebastián y del narrador, dos personajes antitéticos. La primera descripción de Sebastián representa a una ciudad odiosa y plana, que, de acuerdo con su iconoclasia y rebeldía un tanto románticas, él quisiera hacer desaparecer. Dicho sentimiento explicaría el atentado que más adelante llevaría a cabo en la Escuela de Derecho. En el capítulo sexto, cuando Rubén y el narrador sorprenden a Sebastián trabajando en la torre del reloj, en lo más alto de la Escuela, para hacer estallar las tuberías de las aguas fecales, el primero le pregunta si merecía la pena hacerlo:

- ¡Claro que vale! —respondió Sebastián- Si pudiera juntar suficiente mierda bañaría Santiago entero con ella. [...] Yo lo que odio es el país, compadres... ¿van cachando? ¡Aquí aprendí a odiarlo! Sobre todo a Santiago, su Alameda gris, las fuentes de soda con aserrín en el piso, los jardincitos del barrio alto... Aquí aprendí a odiar a toda esta ciudad plana, que huele a gas licuado y perdición. (134)

A través de este mismo personaje se hacen también algunas alusiones veladas a la situación política que se estaba viviendo en Chile: "Me pasé la noche en vela oyendo a la ciudad desde 
aquí arriba. Santiaguito habla dormido. ¿No me creen? Se oían claritas sus pesadillas. Dos gritos, un disparo, la sirena de una patrulla, la explosión a lo lejos que al amanecer nadie sabrá si fue un sueño. Me tiraba el pelo pensando cómo aliviarlo" (135).

En el capítulo octavo es el narrador quien ofrece una visión infernal de la ciudad acorde con la situación represiva y de terror que vivían los ciudadanos:

Una maciza luna de verano se filtraba a través de las horas del reloj. Alumbraba la ciudad como el foco de un campo de concentración. Las calles interminables y vacías en todas direcciones. Ni un soplo de viento. Ni un alma. Tal vez una catástrofe. Tal vez habían evacuado Santiago silenciosamente, mientras estaban escondidos en el entretecho de la Escuela. Estaba por sonar el toque de queda.

Bajaste como si descendieras no cinco pisos, sino cinco círculos concéntricos hasta el fondo mismo de la ciudad vacía. Su cero absoluto. El anillo en el cual vivía su demonio. (141)

Metonímicamente, la descripción del narrador se relaciona también con sus propias actividades, al principio bajo la tutela de Blanco y, más tarde, por su cuenta. Así, el descenso de los cinco pisos de la Escuela lo es al infierno de la ciudad de Santiago, pero también al suyo propio, ya que, en ese momento, al ir a telefonear a Blanco para darle el soplo del atentado de Sebastián, se aceleraba su degradación moral.

\section{La cafetería, el Neuschwanstein}

La cafetería es el lugar donde los personajes del grupo sueñan con huir de una realidad que aborrecen y donde se evidencian las tensiones entre los dos rivales (el narrador y Sebastián). El afiche de Lufthansa del castillo de Neuschwanstein, mandado a construir por Luis II de Baviera, representa uno de los lugares más emblemáticos de Alemania, y por tanto de Europa, adonde los amigos que se reunían cada día en la mesa, situada debajo del afiche, querrían marcharse. No es casual que aparezca de esa manera implícita Luis de Baviera por ser un rey melancólico y soñador, relacionado con el mundo del arte y de la música, mecenas y amigo de Wagner. Como se sabe, el rey loco, muerto misteriosamente en uno de los lagos de Baviera, y sus famosos castillos constituyeron uno de los "paisajes culturales" preferidos por los poetas finiseculares hispanoamericanos. El contraste entre la cafetería, asociada al mundo asfixiante de la Escuela y de la ciudad, y la promisoria Europa del afiche equivalen a la antítesis entre la realidad y el deseo. Por eso, es precisamente en esa misma mesa donde Sebastián lee para el grupo, y en especial para Raquel, las falsas cartas enviadas desde Europa por un amigo que llevaba una vida plena de experiencias y aventuras.

Salvando las distancias, la idea del viaje y la huida a un lugar lejano, reaparece de forma caricaturesca en el Travelers's Night Club, lugar en el que Blanco comparte confidencias con el narrador y le propone colaborar con él. El escenario era una especie de trampantojo donde se simulaba la cubierta de un barco con tres chimeneas y un viaje por distintos lugares, siempre relacionados con el erotismo, sugeridos a través de los bailes.

\section{La fuente con la Dama Verde}

La Dama Verde no es una invención del autor, sino que la fuente con la estatua realmente existe en la Escuela de Derecho de la Universidad de Santiago de Chile. En la 
novela parece tener vida propia y se relaciona metonímicamente con el narrador. Su primera aparición en la historia tiene lugar cuando el narrador toma consciencia de que Sebastián y Raquel están enamorados. Con su frialdad e indiferencia, la estatua, de reminiscencias ancestrales, representa la impotencia del personaje, su incapacidad para resolver las situaciones que lo angustiaban. Más adelante, vuelve el narrador sobre esta misma escena y la estatuilla se posesiona de él exigiéndole que actuara: "Algo dentro de ti se hizo de un hierro mohoso y frío, como el de la estatua que sentiste desdoblarse y entrar bailando desnuda en tu interior, para quedarse. Tomando posesión, golpeaba las puertas, corría las cortinas, abría de par en par tus ventanas al sol de invierno y gritaba: «jdespierta, es hora de actuar, muchacho!»" (63). Sin duda se trata de un guiño a "El ídolo de las Cícladas" de Cortázar, donde la estatuilla se posesiona de Morand y lo lleva a asesinar a su amigo y rival, Somoza, y a su propia esposa, Thérèse. Como en el cuento de Cortázar, también aquí existe un triángulo amoroso. En otro momento, temiendo perder a Raquel y a sus amigos por la influencia que Sebastián ejercía en ellos, acude a la Dama Verde para reflexionar y pedirle consejo.

La estatua era también lugar de sacrificios rituales para los novatos que llegaban a la Escuela: "Varios de sus compañeros fueron sumergidos hasta ofrecerlos semiahogados a la Dama Verde. La que así recibía cada año el sacrificio de otra generación" (26), ya que a mayor resistencia más tiempo quedaban bajo el agua. Y fue allí donde Blanco le descubrió a Raquel la verdad sobre las cartas que les leía Sebastián, arrojándolas a continuación a la fuente. A través del simbolismo de esta última escena podemos concluir que la Dama Verde representa el lugar donde se ahogan los sueños, por eso sería también una representación en abismo de la ciudad de Santiago y del régimen represor.

\section{La Torre del reloj}

Por una parte, este lugar laberíntico, donde se custodiaba el Fondo de Memorias de los Alumnos, era el refugio en el que se había instalado Sebastián, personaje individualista y solitario, que, sin embargo, atraído por Raquel, se había acercado al grupo. A pesar de ser el lugar más alto del edificio, dada la naturaleza distópica de la obra, en él se encuentra lo que Sebastián denomina "la cloaca máxima" (132), ya que este había conseguido reunir en el estanque que allí se encontraba las aguas fecales del edificio para preparar un atentado contra la Escuela. El sitio donde Sebastián había golpeado con el martillo la pared del estanque, con objeto de descubrir el punto débil para hacerlo estallar, se encontraba bajo un grafiti de Bob Dylan: "Ven a tocar en las puertas del cielo" (133), que resulta paradójico en un principio si se piensa en el contenido del estanque. Sin embargo, el verso de Dylan acompaña bien el gesto dionisíaco y destructivo de Sebastián, de quien lo ha perdido todo y quisiera destruirlo todo. El simbolismo de la verticalidad (torre) y horizontalidad (Escuela, ciudad) se neutraliza, porque todo se reduce al cero.

Completan el simbolismo espacial las referencias culturales: a La vida es sueño, por la situación de represión a la que vivían sometidos los ciudadanos bajo el régimen militar; al film Casablanca, por la imposibilidad del amor ideal, y a The Doors, por la banda de rock norteamericana de los sesenta, liderada por Jim Morrison, que marcó la cultura musical de varias generaciones. 


\section{Observaciones finales}

En las conclusiones de este trabajo me interesa poner de relieve de qué manera, dentro de los límites y propiedades de la novela corta, se enfrenta Franz a la problemática de la memoria. Una memoria crítica capaz de contrarrestar la desmemoria sin caer en la tentación de soluciones fáciles o sensacionalistas (Richard, 2002: 188).

Es evidente que las fechas juegan un papel. Franz escribe su historia hacia 1988, el año del plebiscito, con el triunfo del "No", que daría fin a la dictadura chilena y llevaría al poder a Patricio Aylwin, dando lugar al proceso conocido como la Transición. Su relato, no exento de cierto idealismo romántico, se articula mediante diversos elementos simbólicos que el lector puede desvelar sin dificultad, capaces de dar cuenta de la censura, la vigilancia y la persecución por parte del régimen opresor. El más impactante es el vertido de aguas fecales que lleva a cabo el personaje de Sebastián nada menos que desde la torre de la Escuela de Derecho, con todo lo que ello implica, gesto que transforma el Centro - $-\mathrm{y}$, por extensión, la ciudad de Santiago - en una cloaca. ${ }^{15}$ Sin embargo, desde mi punto de vista, atenúa en parte la crítica el hecho de que el narrador-protagonista esté cumpliendo condena, como si en tales circunstancias la justicia fuera capaz de restablecer el orden de las cosas y castigar a los culpables, cuando sabemos que en la práctica no era evidente que así ocurriera. Incluso más tarde, durante algunos años, el consenso político de la Transición rebajó "el tono y la intensidad del reclamo ético en torno al escándalo de la violación de los derechos humanos" (Richard, 2002: 189), y solo a partir de 1998, cuando se produjo el arresto de Pinochet en Londres, puede decirse que comenzó en la sociedad chilena la lucha contra la impunidad.

Desde una perspectiva teórica, Santiago Cero presenta rasgos inherentes a la novela corta. Uno de ellos es el hecho de privilegiar a un personaje que se sitúa en el centro de una constelación, como consecuencia de la compresión narrativa propia del género (Grojnowski, 2000: 107). Otra característica, más significativa aún si cabe, consiste en articular su organización en función de un momento de crisis, de una transformación o cambio en el efecto de las acciones (Grojnowski, 2000: 22-23). En Santiago Cero la transformación del protagonista-narrador se produce a raíz de la aparición de Sebastián en la Escuela — sobre todo desde la lectura de la primera carta - , quien lo desplaza del lugar central que ocupaba en el grupo de amigos universitarios hacia un segundo plano. Ese cambio en su situación lo arrastrará a aliarse con Blanco y a colaborar con el régimen. Por último, en correspondencia con el quiebre social del momento histórico representado, a lo largo del proceso narrativo, el lector asiste a una progresiva disolución de la identidad del protagonista-narrador. En ese sentido, el epígrafe que abre Santiago Cero resulta asimismo revelador: "I am not I; / thou art not he or she; / they are not they" (Evelyn Waugh, Brideshead Revisited). ${ }^{16}$

\footnotetext{
${ }^{15}$ Salvando las distancias, este episodio pudo inspirar el final de Nocturno de Chile: "Y después se desata la tormenta de mierda" (150).

${ }^{16}$ Sobre la pulverización del yo en múltiples identidades sucesivas, en la novela corta, en relación con una imagen de la vida caleidoscópica, atomizada, que ha perdido su sentido de la unidad, véase Blin, 1991: 121-122.
} 


\section{Bibliografía}

AVARIA, Antonio (1990): “Los años sin excusa". Mensaje [Salesianos] 388 (mayo 1990): 151.

BLIN, Jean-Pierre (1991): "Nouvelle et narration au XXème siècle. La nouvelle raconte-t-elle toujours une histoire?" En Bernard Alluin y François Suard (eds.), La nouvelle. Définitions, transformations. Lille, Presses Universitaires de Lille: 115-123.

BOLAÑO, Roberto (2000): Nocturno de Chile. Barcelona, Anagrama.

CÁNOVAS, Rodrigo (1990): "Hacia una histórica relación sentimental de la crítica literaria en estos reinos". Cuadernos Hispanoamericanos 482-483 (agosto-sept. 1990): 161176.

--- (1997): Novela chilena. Nuevas generaciones: El abordaje de los huérfanos. Santiago de Chile, Universidad Católica de Chile.

--- (2000): "Santiago Cero de Carlos Franz, o los caminos de la orfandad". En Verónica Cortínez (ed.), Albaricia: la novela chilena el fin de siglo. Providencia, Santiago, Cuarto Propio: 57-69.

--- (2008): "Desde el Panopticon: lectura de Santiago Cero, de Carlos Franz". Alicante, Biblioteca Virtual de Miguel de Cervantes. Recuperado de. http://www.cervantesvirtual.com/obra-visor/desde-el-panopticon-lectura-de-santiagocero-de-carlos-franz-0/html/01cc9266-82b2-11df-acc7-002185ce6064_2.html\#I_0 [17/7/2018]

COLLYER, Jaime (1990): "De las hogueras a la imprenta. El arduo renacer de la narrativa chilena". Cuadernos Hispanoamericanos 482-483, 2 (1990): 123-135.

--- (1992): “Casus belli”. APSI 415 (del 24 de febrero al 8 de marzo de 1992).

DÍAZ ETEROVIC, Ramón y Diego MUÑOZ VALENZUELA (1986): Contando el cuento. Antología joven narrativa chilena. Santiago de Chile, Sinfronteras.

FRANZ, Carlos: Santiago Cero (1997). Barcelona, Seix Barral. Biblioteca Breve.

--- (1998): "Novelas del fin del mundo". Quehacer 115 (Desco, Centro de Estudios y Promoción del Desarrollo) (sept-oct. 1998): 98-102. Información obtenida de http://www.desco.org.pe/recursos/sites/indice/230/875.pdf [15/09/2018].

GAMBETTI, Rodolfo (1989): “En busca del Franz perdido". Entrevista a Carlos Franz en Las Últimas Noticias (Santiago de Chile), 19 de diciembre de 1989: 36.

GROJNOWSKI, Daniel (2000): Lire la nouvelle. París, HER.

JOCELYN-HOLT LETELIER, Alfredo (1997): "Posfacio. Tras la lectura de Santiago Cero". En Carlos Franz, Santiago Cero. Barcelona, Seix Barral.

LEIBOWITZ, Judith (1974): Narrative purpose in the novella. Albany, Mouton. DOI: https://doi.org/10.1515/9783110883565

OSSES, Mario (1990): “Nosotros los finiseculares”. Cuadernos Hispanoamericanos 482-483, (ago-sept 1990): 137-148.

PIGLIA, Ricardo (2016): Los diarios de Emilio Renzi. Los años felices. Barcelona, Anagrama.

RICHARD, Nelly (1994): La insubordinación de los signos (cambio político, transformaciones culturales y poéticas de la crisis). Santiago de Chile, Cuarto Propio. 
--- (1995): “Lo impúdico y lo público". Revista de Crítica Cultural 11 (nov 1995): 29-34.

--- (2002): “La crítica de la memoria”. Cuadernos de Literatura 8 (15) (ene-jun 2002): 187193.

TIBI, Pierre (1995): "La Nouvelle: Essai de compréhension d'un genre". En Paul Carmignani (ed.), Aspects de la nouvelle (II). Perpignan, Presses Universitaires de Perpignan: 9-76.

VAN ROSSUM-GUYON, Françoise (1970): Critique du roman. Essai sur "La Modification" de Michel Butor. París, Éditions Gallimard.

(C) Carmen de Mora

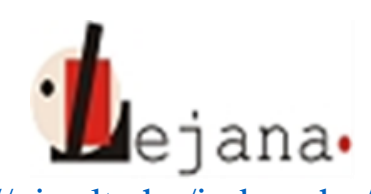

http://ojs.elte.hu/index.php/lejana

Universidad Eötvös Loránd, Departamento de Español, 1088 Budapest, Múzeum krt. 4/C 